\title{
Proprioception Errors in Patients with Cervical Spondylosis at Sagittal Plane
}

\author{
MOSHERA H. DARWISH, Ph.D.*; AMR HASSAN, M.D.**; HEBA A. KHALIFA, Ph.D.* and \\ IBRAHIM A. ABU-ELLA, M.Sc.* \\ The Departments of Neuromuscular Disorder, Faculty for Physical Therapy* and Neurology, Faculty of Medicine**, \\ Cairo University, Cairo, Egypt
}

\begin{abstract}
Background: Cervical spondylosis is a chronic degenerative condition of the cervical spine causing neck pain. Proprioception errors may be contributes to the development and maintenance of cervical spondylosis.

Aim of Study: The study aimed to determine the proprioceptive reposition errors in cervical spondylosis patients.

Patients and Methods: Twenty patients with cervical spondylosis (Group A) and twenty matched healthy subjects (Group B). Their age ranged 30-50 years old were represented the sample of the study. Cervical Range of Motion device (CROM) was used for assessment of proprioception error in flexion and extension.
\end{abstract}

Results: There was significant reduction in absolute angular error of neck flexion, extension at neutral and target head reposition tests in Group B compared to Group A $(p<0.05)$.

Conclusion: Cervical proprioceptive errors are increased in patients with cervical spondylosis in comparison with matched healthy subjects.

Key Words: Cervical spondylosis - Proprioception errorCROM.

\section{Introduction}

CERVICAL spondylosis is a common degenerative condition of the cervical spine in the general population with incidence rate of 83 per 100.000 populations and prevalence of 3.3 cases per 1000 people. It occurs mostly in fourth and fifth decades of life. The etiology of cervical spondylosis is associated with ageing process, and is closely related to the intrinsic axial load imposed by the weight of the cranium lifelong [1].

Correspondence to: Dr. Ibrahim A. Abu-Ella,

E-Mail: ibrahimneuron@gmail.com.
Proprioception provides sensory feedback from the body to the nervous system. It contributes to the maintenance of body alignment [2]. Impairment in proprioception function is one of the main factors contributing to the development and maintenance of neck pain in patients with cervical spondylosis $[3,4]$.

\section{Patients and Methods}

Twenty patients with cervical spondylosis (Group A) and twenty matched healthy subjects (Group B) were participated in the study or represented the sample of the study. Their age ranged from 30-50 years old. The patients were recruited from the Neurology Clinics and Neurology Department in Kaser El-Aini Hospital in the period from April to October 2017. The diagnosis was confirmed by X-rays and MRI. Patients with history of trauma (whiplash injury), cervical myelopathy, and cervical radiculopathy were excluded.

The patients signed a written consent form after receiving information about the study purpose, whole procedures, and possible benefits to ensure full cooperation. The Ethical Committee of Faculty of Physical Therapy, Cairo University approved the study.

Cervical proprioception was measured with the CROM device in sagittal plane (flexion and extension). The CROM has three inclinometers, one to measure in each plane, and is strapped to the head. One gravity dial meter measures flexion and extension. Another gravity dial measures lateral flexion and a compass meter measures rotation with its accuracy reinforced by two magnets placed over the patients shoulders. This device was placed on patient head. Two cervicocephalic sensibility tests were applied (neutral head position and target 
head position) [5] . In Neutral Head Position test (NHP) each patient was asked to sit upright in a comfortable position and look straight ahead [6] The patients instructed to flex or extend head and reposition neck to neutral position while eyes closed. In Target Head Position test (THP) the patient's head was moved to the predetermined target position $(50 \%$ of the maximum range of motion). The head was maintained in this target position for three seconds and the patient was asked to remember this position. The head was returned to neutral position and the patients were asked to reposition actively by moving the head to the target position. When patient reached the reference position, the patient relocation accuracy was measured in degrees with CROM device. Three trials were executed consecutively, and the average of the trials was computed for analysis [7].

\section{Statistical analysis:}

The obtained data were collected and statistically analyzed using the descriptive statistics (median, Interquartile Range). Mann-Whitney U-test was used for comparison between both groups. $p$ value $<0.05$ was considered significant [8].

\section{Results}

The results of current study revealed that there was significant reduction in absolute angular error of neck flexion, extension at both testing position (neutral and target head position tests in Group B compared to Group A $(p<0.05)$ (Table 1).

Table (1): Descriptive statistics (median and interquartile range) andcomparison tests for proprioception errors between both groups.

\begin{tabular}{lcccc}
\hline Variables & $\begin{array}{c}\text { Testing } \\
\text { positions }\end{array}$ & $\begin{array}{c}\text { GI } \\
\text { median } \\
\text { (IQR) }\end{array}$ & $\begin{array}{c}\text { GII } \\
\text { median } \\
\text { (IQR) }\end{array}$ & $\begin{array}{c}p \text { - } \\
\text { value }\end{array}$ \\
\hline $\begin{array}{l}\text { - Absolute } \\
\text { angular error } \\
\text { of neck }\end{array}$ & NHP & $5(5.58)$ & $0(0)$ & $0.0001^{*}$ \\
flexion & & $5(4.33)$ & $0(0.75)$ & $0.0001^{*}$ \\
- Absolute & NHP & $4.33(4.915)$ & $0(0)$ & $0.0001^{*}$ \\
$\begin{array}{l}\text { angular error } \\
\text { of neck }\end{array}$ & THP & $3.33(3.67)$ & $0(0)$ & $0.0001^{*}$ \\
extension & & & & \\
\hline $\begin{array}{l}\text { NHP }: \text { Neutral Head Position test. } \\
\text { THP : Target Head Position test. } \\
\text { : Significant }=p<0.05 .\end{array}$ & & \\
\end{tabular}

\section{Discussion}

The results of the present study showed greater errors of proprioception in patients with cervical spondylosis comparing to controlled healthy sub- jects. The errors were statistically significant in flexion and extension in both neutral and target head positioning tests.

The pain in cervical spondylosis patients might also be the reason for altered proprioception as pain is capable of inducing changes in muscle spindles discharge and the proprioceptive properties of brainstem neurons. Disturbance of the proprioceptive system has been shown to interfere with motor control, and it has been suggested that aberrant motor control may expose the spinal components to abnormal and repetitive strain [9-11]

There was a tendency for the cervical spondylosis patients to overshoot the target position, as greater errors occurred during repositioning from all tested positions to the NHP and THP. This might be due to overcompensation taken by other muscles and an increased effort to reach the target. The overshooting phenomenon in the present study indicates decreases in proprioceptive afferent inputs, presumably from the activating neck muscles. Some patients demonstrated jerky/altered movement patterns in the cervical spondylosis group which is because of decreases proprioceptive cues from the sources which results in searching the targets and resulting in jerky movements [12,13].

Poor head posture, cause excessive joint and muscle loading, and subsequently influencing weakness of the deep cervical muscles. Muscle imbalance, including weakness of cervical flexors and shortening of cervical extensors, has been reported in patients with cervical spondylosis. These abnormal changes in the muscles can lead to disruption of afferent input from the muscle spindles, which may have an adverse effect on joint position sense [14-16].

\section{Conclusion:}

Cervical proprioceptive errors are increased in patients with cervical spondylosis in comparison with matched healthy subjects.

Financial support and sponsorship:

Nil.

\section{Conflicts of interest:}

There are no conflicts of interest.

\section{References}

1- REDDY R.S., A.G., S.K.: Proprioceptive reposition errors in subjects with cervical spondylosis. International Journal of Health Sciences \& Researc, 1 (2): 65-73, 2012. 
2- LEE H., CHENG C. and LIAU J.: Correlation between proprioception, muscle strength, knee laxity, and dynamic standing balance in patients with chronic anterior cruciate ligament deficiency. The Knee, 16 (5): 387-91, 2009.

3- WEON J., OH J., CYNN H., KIM Y., KWON O. and YI C.: Influence of forward head posture on scapular upward rotators during isometric shoulder flexion. Journal of Bodywork and Movement Therapies, 14 (4): 367-74, 2010.

4- KANG J., PARK R., LEE S., KIM J., YOON S. and JUNG K.: The Effect of the Forward Head Posture on Postural Balance in Long Time Computer Based Worker. Annals of Rehabilitation Medicine, 36 (1): 98, 2012.

5- REVEL M., DESHAYS A. and MINGUET M.: Cervicocephalic kinesthesia sensibility in patients with cervical pain. Arch. Physical. Med. Rehab., 72: 288-9, 1991.

6- TENG C., CHAI H., LAI D. and WANG S.: Cervicocephalic kinesthetic sensibility in young and middle-aged adults with or without a history of mild neck pain. Manual Therapy, 12 (1): 22-8, 2007.

7- REDDY R., ALAHMARI K. and SILVIAN P.: Test-retest reliability of assessing cervical proprioception using cervical range of motion device. Saudi Journal of Sports Medicine, 16 (2): 118, 2016.

8- KIRKWOOD B. and STERNE J.: Essential Medical Statistics 2E. Chicester: Wiley, 2015.

9- GRIEVE G.: Common vertebral joint problems. Edinburgh: Churchill Livingstone, 1998.
10- RIBOT-CISCAR E. and ROLL J.: Ago-antagonist muscle spindle inputs contribute together to joint movement coding in man. Brain Research, 791 (1-2): 167-76, 1998.

11- DJUPSJÖBACKA M., JOHANSSON H., BERGENHEIM M. and SJÖLANDER P.: Influences on the $y$-musclespindle system from contralateral muscle afferents stimulated by $\mathrm{KCl}$ and lactic acid. Neuroscience Research, 21 (4): 301-9, 1995.

12- LAM S.S., JULL G. and TRELEAVEN J.: Lumbarspine kinesthesia inpatientswith longus colli and sternocleidomastoid muscles: An electromyo-low back pain. Journal of Orthopaedics and Sports Physical graphic study. Anatomic Record., 177: 471-84, 1973. Therapy, 29: 294-9, 1999.

13-GORDON J., GHILARDI M.F. and GHEZ C.: Impairments of reaching movements in patients without proprioception I. Spatial errors. Journal of Neurophysiol, 73 (1): 34760, 1995.

14- DOVER G. and POWERS M.E.: Reliability of joint position sense and force-reproduction measures during internal and external rotation of the shoulder. Journal of athletic training, 38 (4): 304, 2003.

15- SZETO G., STRAKER L. and RAINE S.: A field comparison of neck and shoulder postures in symptomatic and asymptomatic office workers. Applied Ergonomics, 33 (1): 75-84, 2002.

16- PROSKE U.: Kinesthesia. The role of muscle receptors. Muscle and Nerve, 34 (5): 545-58, 2006.

\section{إضطراب الإحساس العميق للرقبة فى مرضى خشونة الرقبة

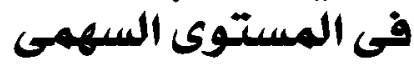

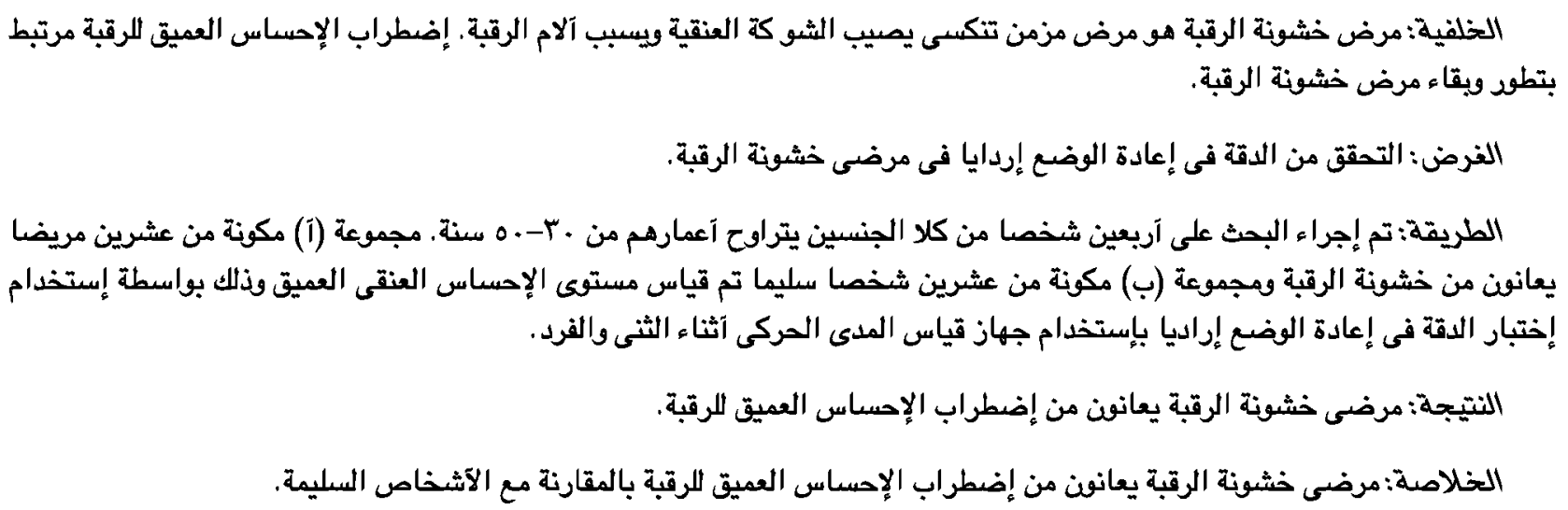

